Original Research Paper

\title{
Local Climate Trends and Farmers' Perceptions in Southern Tigray, Northern Ethiopia
}

\author{
${ }^{1,2}$ M.G. Abrha and ${ }^{1}$ S. Simhadri \\ ${ }^{1}$ Department of Geography, Faculty of Science, Osmania University Hyderabad-500007, India \\ ${ }^{2}$ Department of Geography and Environmental Studies, Aksum University, Aksum, Tigray, Ethiopia
}

\author{
Article history \\ Received: 23-02-2015 \\ Revised: 01-08-2015 \\ Accepted: 18-09-2015 \\ Corresponding Author: \\ M.G. Abrha \\ Department of Geography and \\ Environmental Studies, Aksum \\ University, Aksum, Tigray, \\ Ethiopia \\ Email: misge682000@gmail.com
}

\begin{abstract}
This study aimed to investigate changes in local climate, farmers' perception to the change and factors affecting perception of farmers to climate change. For trend analysis, we gathered station based rainfall records for the period 1978-2012, while for perception analysis survey was carried out. 600 farming households were randomly selected from four districts using a multi-stage sampling method. Nonparametric analysis was used for analyzing trends and testing significance. Farming households were asked their observation about changes in local climate using structured questionnaires. We also utilized logistic regression to identify factors that influenced perceptions of farming households on climate change. Results indicate that while annual rainfall showed no change across the region, Kiremt and Belg rainfalls exhibited significant increasing and decreasing trends in the last three decades respectively. The study confirmed that the change in rainfall trend varies by agro-ecology. Kiremt rainfall in the lowlands increased by about $106 \mathrm{~mm} / \mathrm{decade}$; yet, highlands got nonsignificant change. Besides, when the highlands lost significant amount of Belg rainfall $(35 \mathrm{~mm} / \mathrm{d})$, lowlands didn't show any significant reduction. As to perception, about 87 and $50 \%$ of respondents perceived Belg and Kiremt rainfall decreasing respectively where their observation was more or less consistent with statistical findings. This study learned that gender, education, farm experience, extension, climate information, economic status, drought experience and local agro-ecology positively influenced farmers' perception. Yet, irrigation negatively affected farmers' perception. Results suggest further works in the areas of information dissemination, inclusion of local knowledge in adaptation programs and irrigation developments to reduce impacts.
\end{abstract}

Keywords: Seasonal Rainfall, Climate Change, Farmers' Perceptions, Perception Determinants, Northern Ethiopia

\section{Introduction}

Although agriculture has frequently been challenged by climate change effects (NMA, 2007), the sector remains the backbone of the Ethiopian economy. It directly supports about $85 \%$ of the population for employment and livelihood. It contributes about $50 \%$ of the country's Gross Domestic Product (GDP) and generates about $90 \%$ of the export earnings, with smallscale farmers dominating the production of crops. However, rainfall is the foremost source of water for crop production as irrigation covers not more than 5\% of the cultivated land in the country (Awulachew et al.,
2010). Therefore, success or failure in agricultural sector implies enormous effect, ranging from the survival of the subsistence farmers to the state of country's economy at large.

Ethiopia's climate is changing and a number of projections emphasized further changes are on the way. Projections expect warming in all seasons across the country, which may cause a higher frequency of heat waves and higher rates of evaporation (Conway and Schipper, 2011). Also, a likely increase in mean annual rainfall in East Africa highlands including Ethiopia is anticipated (Christensen et al., 2007). More specifically, National Meteorological Agency (NMA) 
expects rainfall to decline in northern part, whereas southern part of the country might see an increasing trend of rainfall as much as 20\% (NMA, 2007).

Rising temperatures, increasingly erratic rainfall, more frequent and severe floods and droughts have significant concerns especially to those highly dependent on natural resources, like agriculture, for their livelihoods. In agriculture sector, the consensus is that changes in temperature and precipitation will result changes in land and water regimes that will later affect agricultural productivity (WB, 2003).

Ethiopia is a large country comprised of different agro-ecologies and climate features resulted from its location and altitude variations, which implies the need for climate investigations at local level. Some studies were carried out in different parts of the country because large-scale climate projections and trend generalizations may not necessarily reflect situations at local and agroecological level. Bewket (2009) in his study of rainfall variability and crop production in Amhara region of Ethiopia, found increasing annual and Kiremt (summer) rainfall in Dessie and Lalibela stations. He also learned a drop in Debretabor (Kiremt) and Dangla (Belg rains) in central-west part of the country in the period 1975-2003. Dereje et al. (2012) also found positive Kiremt rainfall trends at Bahirdar, Gondar, Srinka and Mettema stations, whereas negative trends of Belg (spring) rainfall were identified at Kombolcha and Srinka stations in the period of 1978-2008. Another study by Hadgu et al. (2013) learnt negative trends for both Belg and Kiremt rainfall in northern Ethiopia, though trends in Kiremt were non-significant. Besides, Seleshi and Zanke (2004; Vste et al., 2013) learned no trend for all annual and seasonal rainfall in Northern Ethiopia in general. These studies, although in Northern and central part of the country, are good indicators of how climate elements vary across locations in Ethiopia.

Southern Tigray is an area highly vulnerable and sensitive to climate related extreme events such as droughts. The historic drought of 1984/5 had left serious damages in this part of the country. From then onwards, reports from DPPC (1999; 2004; FAO, 2008; 2009) indicated repeated failures in crop production because of localized droughts associated to variable and erratic rainfall in Belg and Kiremt seasons. Reports from these organizations show partial or total failure of production at least in 11 of the last 17 years due to rainfall variability since 1997.

Despite increasing intensity and frequency of climate hazard in southern Tigray, empirical studies are deficient on this field. With global warming a certainty, it is imperative to make investigations on climate elements at local level. Investigating how farmers perceive climate change and how they respond to the changes will have valuable inputs for further development directions. How local people perceive climate change determines how they formulate strategies to reduce possible impacts of those changes on their livelihoods (Deressa et al., 2010; Prager and Posthumus, 2010). Therefore, local perspectives can be combined with scientific climate scenarios to draw policy recommendations for future adaptation strategies (Patino and Gauthier, 2009).

Yet, farmers' perception and adaptation practices to climate change are context and location specific. Societies differ in culture, education, demographics, resource endowments, biophysical and institutional characteristics. This heterogeneity influence the way they perceive change in their local climate and the way they respond to the change (Maddison, 2007; Posthumus et al., 2010).

Some attempts were made to analyze how farmers perceive climate change in the country. Admassie and Adnew (2007; Deressa et al., 2010; Hadgu et al., 2013) investigated farmer's perceptions to local climate change and adaptation strategies. However, they did not see how consistent farmers' perceptions were with realities (statistical discoveries) and how socioeconomic factors influence perceptions. It would be more useful when farmers' perceptions are surveyed and compared with statistical discoveries and factors affecting perceptions are explicitly identified. The fact that perception leads to adaptations means we have to identify barriers of perceptions and pave a way for effective adaptation strategies.

The purposes of this study, therefore, were (1) to investigate trends of seasonal and annual rainfalls; (2) to identify farmers' perceptions on trends of local climate and compare them with findings of statistical analysis and (3) to identify factors influencing farmers' perception to climate change and extent of influence in southern Tigray.

\section{Method}

\section{Study Area Description}

Southern Tigray is one of the seven zones in Tigray regional state of Ethiopia located between $12^{\circ} 14^{\prime} 53.9^{\prime \prime}-13^{\circ} 06^{\prime} 08^{\prime \prime} \mathrm{N}$ latitude and $39^{\circ} 10^{\prime} 45.7^{\prime \prime}$ 39 53'41.7" E longitude. Having a total area of 499,616.1 ha, the study area comprises five rural districts (Alaje, Alamata, Endamehoni, Ofla and Raya-azebo) and three town administrations (Alamata Town, Korem and Maichew), as in Fig. 2.

Rugged topography including mountains, plateaus, valleys and gorges characterize the physical landscape of Southern Tigray. Generally, the topography contains four main traditional divisions of arable Ethiopia, as in Fig. 1. Kola/lowland that cover $40.4 \%$ of the area ranges between 1400 to 1800 mean above sea level (m.a.s.l.) and has low rainfall and high temperatures relative to 
others. Woina-dega/middle highland shares $29 \%$ of area extending between 1800-2400 m.a.s.l. This part has medium rainfall amount and moderate temperature. Dega/highland extending between 2400-3400 m.a.s.l has relatively higher rainfall and cooler temperatures and covers about $30 \%$. Wurch/very-cold areas are locations of above 3400 m.a.s.l with high rainfall and low temperatures and cover $0.45 \%$ of the study area.

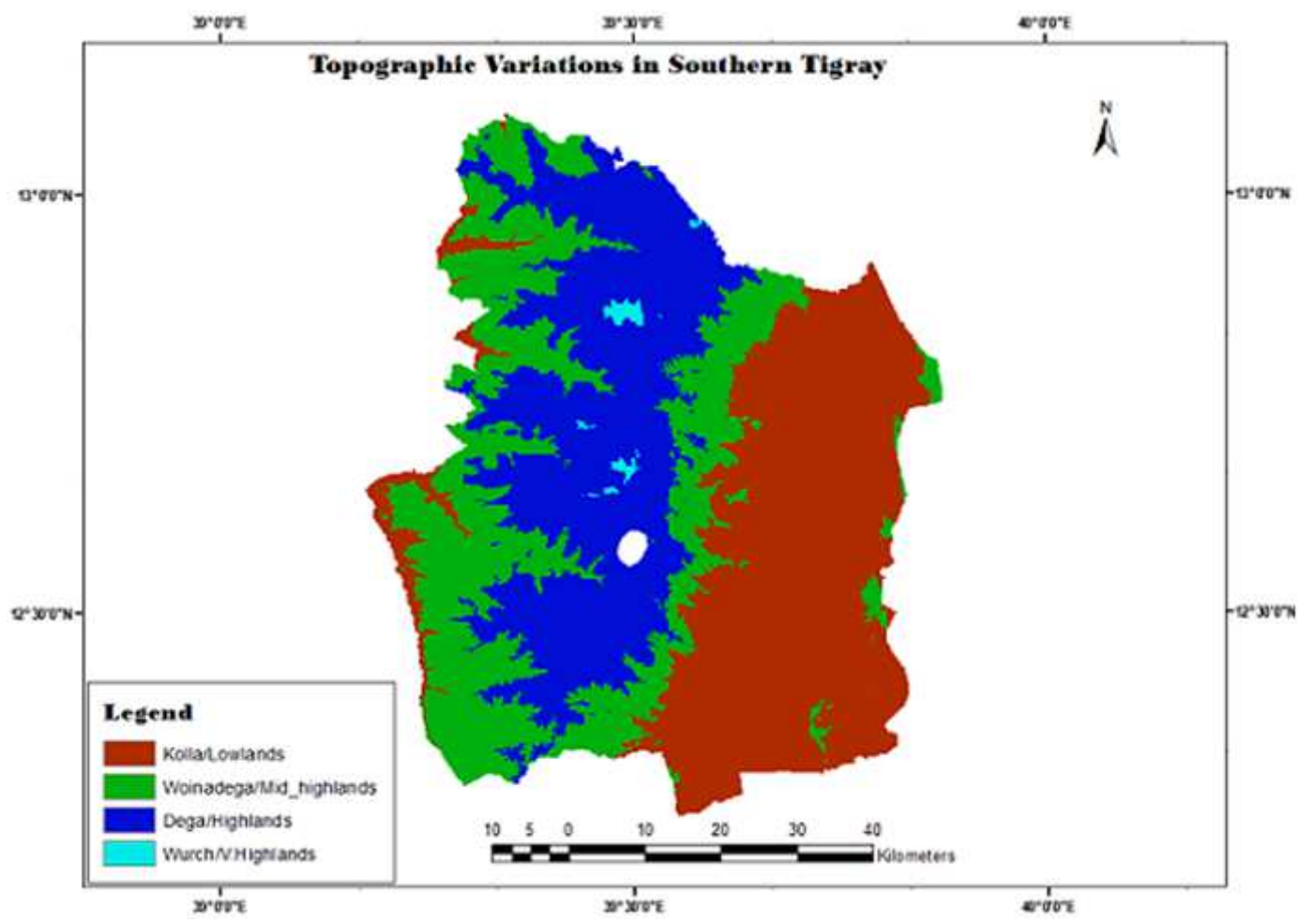

Fig. 1. Variations in topography and agro-ecological zones in Southern Tigray

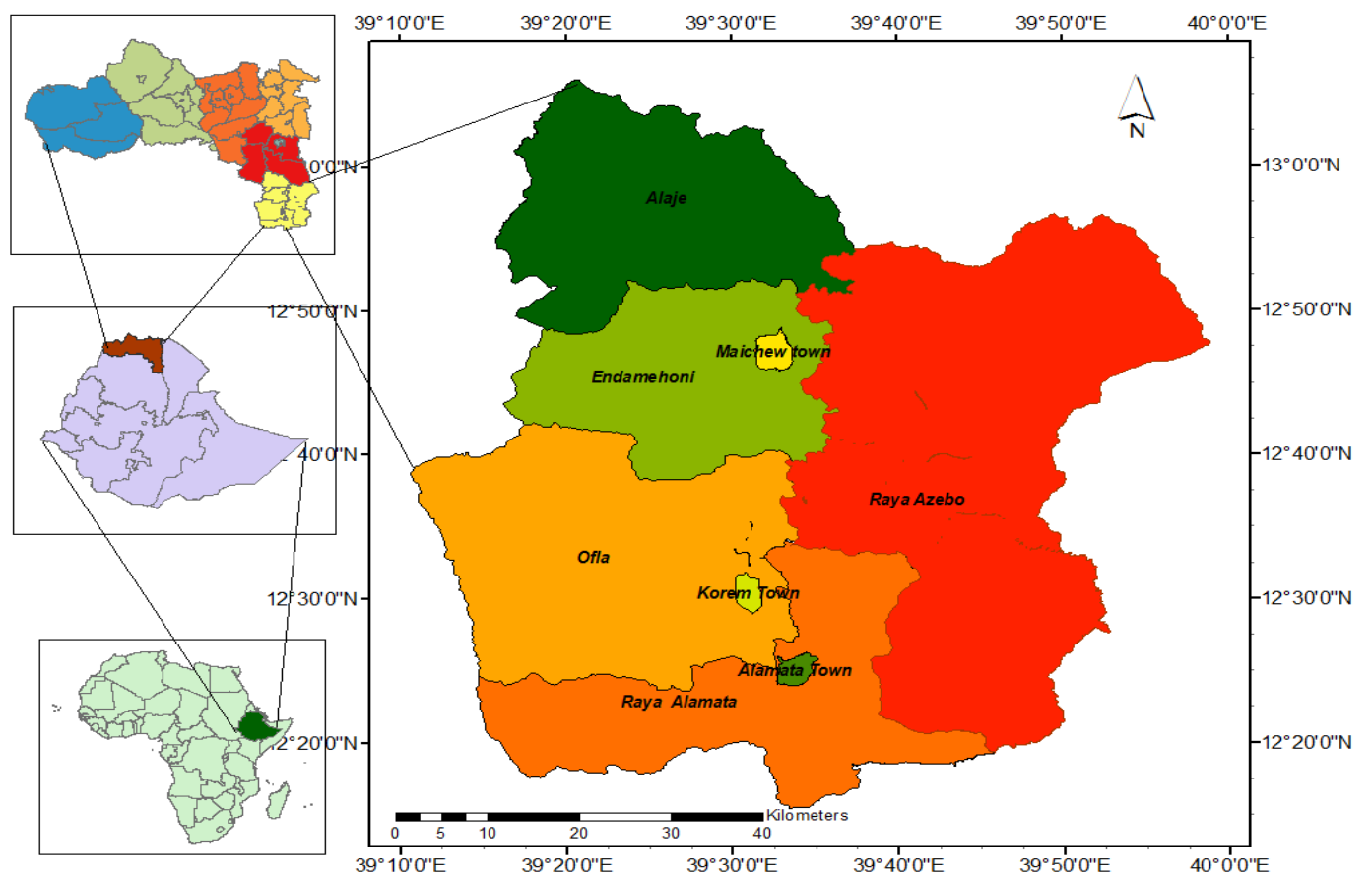

Fig. 2. Location of study area Together with districts that comprised Southern Tigray Zone 
Ofla-alaje highland and kola (lowland) agro-ecologic zones are the two dominant agro-ecological zones in southern Tigray where the former is located in western part (including Alaje, Endamehoni and Ofla districts) comprising the highlands and the later one in the eastern part (including Alamata and Raya-azebo districts) comprising lowlands, as in Fig. 1 above. The two agroecological zones are agriculture-based mixed farming production systems in which crop cultivation is practiced along with livestock rearing (MARD, 2009).

The area has mainly semiarid climate with a bimodal rainfall type. The main rainy season which lasts from June to September (locally called Kiremt) follows the premonsoon rainy season, February to May, (locally called Belg) that adds a small rain to the area. Agricultur is rain-fed and led by small-scale farmers with an average landholding size of less than one hectare per household. Like the rest of country, agriculture is mainstay of the economy, where it directly supports for about $86.4 \%$ of the population for employment and livelihood. Total polulation of the study areas was 717,420 with a population density of 144 people per $\mathrm{Km}^{2}$ in 2013 (CSA, 2012).

In addition, the sector is highly susceptible to climate variability, seasonal shifts in rainfall, resulting in drought. Almost annually the study area experiences localized droughts because of abnormally low and untimely rainfall causing crop failure to jeopardies rural livelihoods and food security (DPPC, 2006; FAO, 2008; 2009). Southern Tigray was selected for this study because recurrent drought and crop failures are common in this area.

\section{Data and Sampling Procedure}

This study is made based on a cross-sectional survey design where data are collected from representative samples at a specific point in time. Historic temperature and rainfall records of varied duration were assembled for Alamata, Maichew and Korem stations from National Meteorological Services Agency of Ethiopia (NMSAE). WMO recommended a minimum of 30 years data series required to detect trend in climatic study. Accordingly, three stations delivered rainfall records recommended years, as in Table 1. Although offered, temperature records were broken repeatedly in all stations. Therefore, temperature trend analysis was impossible due to absence of uninterrupted records.
Considering the maximum flexible thresholds of $10 \%$ missing values adopted by Ngongondo et al. (2011), Alamata, Maichew and Korem observatory stations were taken for rainfall trend analysis once missing values were filled by averaging neighboring records.

Agro-ecologically, highland contains Maichew and Korem meteorological stations, whereas the lowland agro-ecology contains Alamata station. This categorization helps to have a comparative analysis at station, agro-ecological and areal level to give highlights about how rainfall characteristics are spatially distributed in the study area.

Farmers' ability to perceive climate change is a first key step for making decision to adapt. To identify how farming Households ( $\mathrm{HHs}$ ) perceive the state of climate in their locality, a survey was conducted between April and October 2013. The survey covered twenty Tabias of four districts (Alamata, Endamehoni, Ofla and Rayaazebo), five Tabias from each. Using multistage sampling procedure, $30 \mathrm{HHs}$ were randomly selected from each Tabia to constitute $600 \mathrm{HHs}$ in total.

Structured and semi-structured questionnaires were used to ask selected farming $\mathrm{HH}$ heads to express their perceptions on whether changes have been observed on climatic elements and associated extreme events in their localities in last two decades. Selected Tabias from which respondents were randomly selected are showed in Fig. 3.

\section{Data Analysis}

Different methods of data analysis were used in this study. Some of the major are discussed as follows:

\section{Areal Weighted Averages}

For agro-ecological/regional trend analysis, areal weighted average rainfall was applied based on monthly rainfall series of all stations located within an area under consideration. We follow the Nicholson (1985) formula to calculate our areal weighted average rainfall:

$$
R_{j}=\frac{\sum X_{i j}}{I_{j}}
$$

Where:

$$
\begin{aligned}
R_{j}= & \text { Areal } / \text { regional integrated rainfall for year } j \\
X_{i j}= & \text { Rainfall record at station } i \text { for year } j \\
I_{j}= & \text { The number of stations having rainfall record for } \\
& \text { year } j
\end{aligned}
$$

Table 1. Meteorological stations, geographic characteristics and available rainfall records

\begin{tabular}{lllllll}
\hline Station name & Altitude $(\mathrm{m})$ & Latitude & Longitude & Years of observation & Years of no data & Agro-ecol. Zone \\
\hline Alamata & 1578 & $12^{\circ} 25^{\prime} 09^{\prime \prime} \mathrm{N}$ & $39^{\circ} 33^{\prime} 22^{\prime \prime} \mathrm{E}$ & $1978-2012$ & 1981,90 and 91 & Low land \\
Korem & 2478 & $12^{\circ} 30^{\prime} 28^{\prime \prime} \mathrm{N}$ & $39^{\circ} 31^{\prime} 11^{\prime \prime} \mathrm{E}$ & $1980-2012$ & 1980 and 81 & Highland \\
Maichew & 2440 & $12^{\circ} 47^{\prime} 02^{\prime \prime} \mathrm{N}$ & $39^{\circ} 32^{\prime} 00^{\prime \prime} \mathrm{E}$ & $1978-2012$ & 1989 and 90 & Highland \\
\hline
\end{tabular}

Source: Meteorological data series from NMAE, 2013 


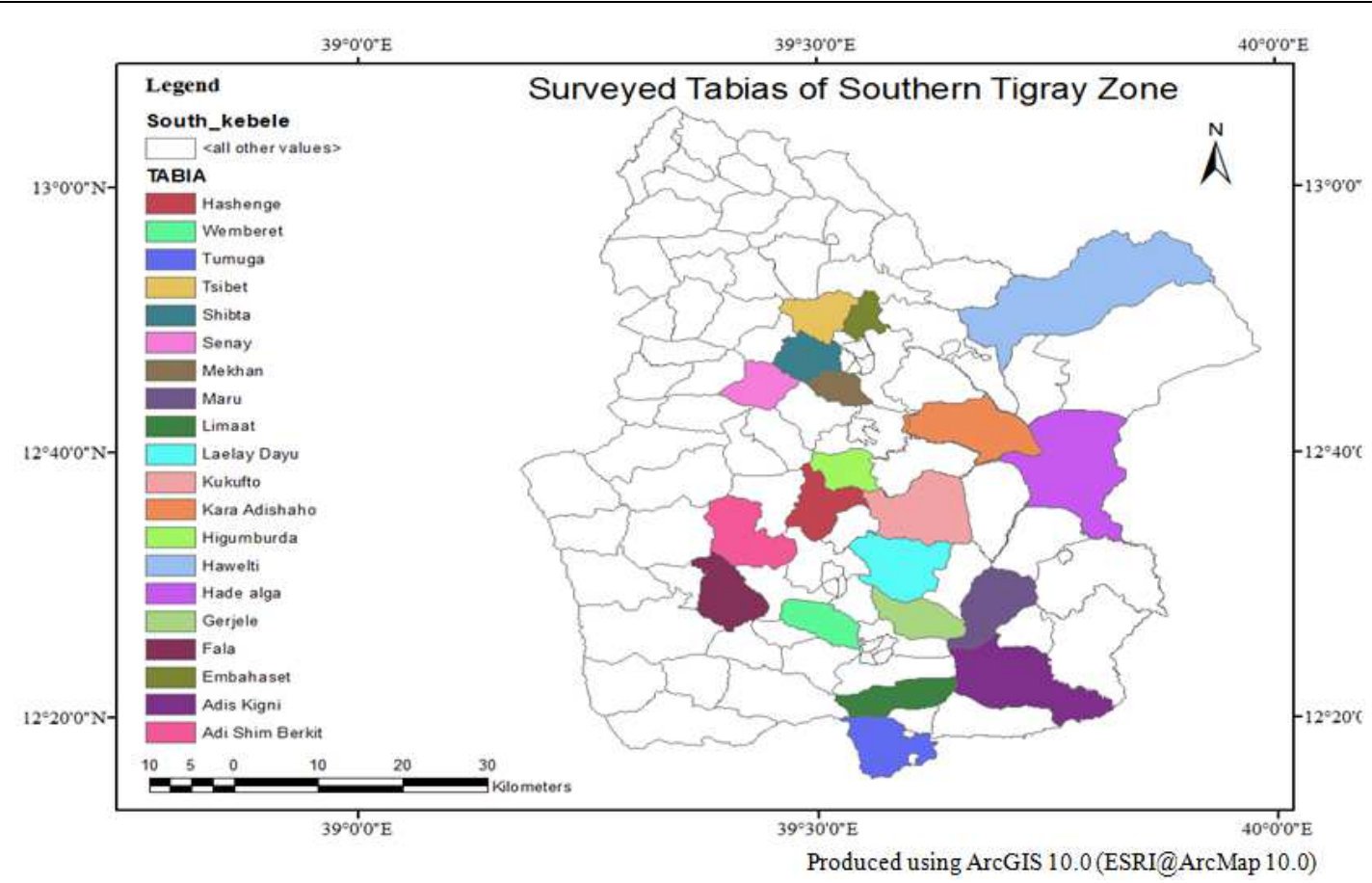

Fig. 3. Surveyed Tabias of Southern Tigray Zone, 2014

\section{Detecting Outliers}

As Gonzalez-Rouco et al. (2011) urges, primary emphasis was given to identify outliers in the climate data. Outliers are values greater than a threshold value of a specific time series data that can affect detection of in homogeneity. For non-normally distributed data like rainfall, the Turkey fence is recommended for trimming the outlier (Ngongondo et al., 2011). The Turkey fence used in this study was set only for upper limit assuming that any rainfall value below zero is automatically an outlier. Values outside the Turkey fence were considered as outliers and such outliers were set to a limit value corresponding to $\pm 1.5 \times \mathrm{IQR}$. Hence, the fence is represented as:

$$
\left[Q_{3}+1.5 \times I Q R\right] \text { as upper limit }
$$

where, $Q_{3}$ is upper quartile point, 1.5 standard deviations from the mean and IQR is interquartile range.

\section{Mann-Kendall Analysis}

Mann Kendall analysis is a statistical test widely used for analyzing trends in climatologic (Mavromatis and Stathis, 2011) and in hydrologic time-series studies (Yue and Wang, 2004). There are two advantages of using this test. First, it is a non-parametric test and does not require data to be normally distributed. Second, it has low sensitivity to abrupt breaks due to inhomogeneous time series (Tabari et al., 2011). Any data reported as non-detects are included by assigning them a common value that is smaller than the smallest measured value in the data set (Blackwell, 2012). Data values are evaluated as an ordered time series. Each data value is compared to all subsequent data values. The initial value of the Mann-Kendall statistic, $S$, is assumed to be 0 (e.g., no trend). If a data value from a later period is higher than a data value from an earlier period, $S$ is incremented by 1 . On the other hand, if the data value from a later period is lower than a data value sampled earlier, $S$ is decremented by 1 . According to this test, the null hypothesis $\left(H_{0}\right)$ assumes that there is no trend $(S=0)$ and this is tested against the alternative hypothesis $\left(H_{1}\right)$, which assumes that there is a trend $(S$ $\neq 0)$ (Onoz and Bayazit, 2012).

Let $x_{1}, x_{2}, x_{3}, \ldots, x_{n}$ represent $\mathrm{n}$ data points where $x_{j}$ represents the data point at time $j$. Then the Mann-Kendall statistic $(S)$ is given by:

$$
S=\sum_{i=1}^{n-1} \sum_{j-1+1}^{n} \operatorname{sign}\left(X_{j}-X_{i}\right)
$$

$$
\operatorname{Sign}\left(X_{j}-X_{i}\right)=\left\{\begin{array}{ccc}
+1 & \text { if } & \left(X_{j}-X_{i}\right)>0 \\
0 & \text { if } & \left(X_{j}-X_{i}\right)=0 \\
-1 & \text { if } & \left(X_{j}-X_{i}\right)<0
\end{array}\right.
$$

where, $S$ is Mann-Kendal's test statistics; $X_{i}$ and $X_{j}$ are rainfall values for years $i$ and $j(j>i)$ and $n$ is length of the time series (30 years for instance) (Motiee and McBean, 2009). A positive/negative value of $S$ indicates an upward/downward trend (Drapela and Drapelova, 2011). 
Kendall (1975) assumed for a data series $n \geq 10$, the statistic $S$ is approximately normally distributed with the mean and variance and computed (Yenigun et al., 2008) as follows:

$$
E(s)=0
$$

The variance $\left(\sigma^{2}\right)$ for $S$-statistics, in a situation where there may be ties (same values) in the $x$ value, is given by:

$$
\operatorname{Var}(S)=\frac{n(n-1)(2 n+5)-\sum_{i=1}^{m} t_{i}\left(t_{i}-1\right)\left(2 t_{i}+5\right)}{18}
$$

where, summation term in the numerator is used only if the data series contains tied values, $m$ is the number of tied groups and $t_{i}$ is the number of data points in the tied group. The standard test statistic $Z_{S}$ is calculated as follows:

$$
Z_{s}=\left\{\begin{array}{ccc}
\frac{S-1}{\sqrt{\operatorname{var}(S)}} & \text { if } & S>0 \\
0 & \text { if } & S=0 \\
\frac{S+1}{\sqrt{\operatorname{var}(S)}} & \text { if } & S<0
\end{array}\right.
$$

The presence of a statistically significant trend is evaluated using Mann-K value. In a two-sided test for trend, the null hypothesis $\left(H_{0}\right)$ should be accepted if $\mid$ Mann- $K \mid<Z_{1-\alpha / 2}$ at a 0.05 level of significance. $Z_{1-\alpha / 2}$ is the critical value of Mann-K from the standard normal table. For instance, for 5\% significance level, value of $Z_{1-\alpha / 2}$ is 1.96 .

\section{Theil-Sen's Slope}

Theil-Sen slope (Sen, 1968), also known as "Kendall's slope" or "Nonparametric linear regression slope", is an alternative to the standard linear regression slope. It is popular in earth sciences (meteorology and climatology) for measuring temperatures and precipitations over time. A straight line can represent the Theil-Sen slope, but, it is "distribution free" and permits use of merely ordinal measurement scales. This method could also be used with missing data and remain unaffected by outliers or gross errors (Karpouzos et al., 2010). Slope (change per unit time) was estimated following the procedure of Sen (1968) and detail outline of the procedure is given in Partal and Kahya (2006) and Karpouzos et al. (2010).

\section{Meteorological Drought Assessment}

Meteorological drought is a type of drought that occurs due to prolonged period of below average precipitation to cause natural shortage of available water. To support comparisons between perception of drought occurrences and statistical findings, the Standardized Anomaly Index (SAI) was used as a tool. SAI was used to determine dry and wet years and assess frequency and severity of meteorological droughts from rainfall records, as in Bewket (2009; Hadgu et al., 2013). The formula was:

$$
S=\frac{\left(P_{t}-P_{m}\right)}{\sigma}
$$

where, $S$ is standardized anomaly index; $p_{t}$ is total annual rainfall of year $\mathrm{t} ; p_{m}$ is long time average annual rainfall and $\sigma$ is standard deviation of annual rainfall over period of observation. Values of $\mathrm{S}$ will be cast in to one of the drought severity classes; such as, extreme drought $(S<$ 1.65), severe drought $(-1.28>S>-1.65)$, moderate drought $(-0.84>S>-1.28)$ and no drought $(S>-0.84)$. The class intervals correspond with the 95, 90and 80 percentiles assuming that annual rainfall data are normally distributed.

\section{Approach to Detect farmers' Perception of Local Climate Change}

Different studies adopt various systems to determine whether farmers perceive climate change. Detecting perception of farmers on climate change is a difficult task in developing countries, especially in Africa. Farmers in developed world have access to the wealth of climate and weather information; they easily can learn about changes and variations in climate without having to sense them. However, the case is different when African farmers use various traditional methods to forecast weather and climate. These farmers detect longterm climate fluctuations and changes ones after they sense it, for which sensitivity matters individually.

Studies made in Africa in this case applied different approaches to identify perceptions. Meze-Hausken (2004; Deressa et al., 2010) in Ethiopia, Komba and Muchapondwa (2012) in Tanzania and Maddison (2007) followed the easiest approach, which is to ask farmers if they have observed changes in their local climate across some decades. Their results show mixed results on farmers' ability to detect climate changes in their environment.

Following this easy approach, we made a survey and asked sample farming-households if they have seen any change in climate variables, mainly rainfall and temperature in the last two decades (1990s and 2000s). Then, we checked if findings from the survey are consistent with reality on ground.

\section{Logistic Regression}

Farmers' perception to climate change is a precondition for effective adaptation. Evidences in 
Africa reveal that large numbers of agriculturalists already perceived hotter climate, less predictable rains with shorter in duration and then started farm level responses. However, Perceptions are context and location specific due to heterogeneity in factors that influence them such as culture, education, gender, age, resource endowments, agro-ecology and institutional factors (Maddison, 2007; Deressa et al., 2010).

The study used logistics model to identify factors influencing farmers' perceptions to climate change, as in Ndambiri et al. (2012). In the model, dependent variable is dichotomous in its nature, taking value of 1 or 0 . Although Ordinary Least Squares (OLS) method may compute estimates for the binary choice models, certain assumptions of the classical regression model will be violated. These include non-normality of disturbances, heteroscedastic variances of the disturbances and questionable value of $R^{2}$ as a measure of goodness of fit (Gujarati, 2003). For instance, given:

$$
y_{i}=\beta_{0}+\beta_{i} \chi_{i}+\varepsilon_{i}
$$

Where:

$$
\begin{aligned}
y_{i}=1= & \text { If a farmer perceives climate change and } y_{i}=0 \\
& \text { if a farmer does not } \\
\beta_{0}= & \text { Intercept } \\
\beta_{i}= & \text { Parameter to be estimated } \\
\chi_{i}= & \text { Variable in question } \\
\varepsilon_{i}= & \text { Disturbance term. }
\end{aligned}
$$

This model is a typical linear regression model but, because the regressand is binary or dichotomous, it is called a Linear Probability Model (LPM). However, in regression model, when dependent variable is dichotomous in nature, taking value 1 or 0 , use of linear probability models becomes a major problem. This is because; predicted value can fall outside the relevant range of zero to one probability value. Thus, if linear probability models are used, results may fail to meet statistical assumptions necessary to validate conclusions based on the hypothesis tested (Feder et al., 1985).

Gujarati (2003) recommended Logit and probit models to overcome the problem associated with LPM. These models use Maximum Likelihood Estimation (MLE) procedures and ensure that probabilities are bound between 0 and 1 . Both logit and probit transformations estimate cumulative distribution, thereby eliminating the interval 0,1 problem associated with LPM. The logistic cumulative probability function can be represented by:

$$
P_{i}=F\left(Z_{i}\right)=\frac{1}{1+e^{-z_{i}}}
$$

where, $P_{i}$ is the probability that $i$ th person will be in $I$ first category, $Z_{i}=\beta_{0}+\beta_{i} \chi_{i}+\varepsilon_{i}$ where $\beta_{0}$ is intercept of the model; $\beta_{i}$ is model parameters to be estimated; $\chi_{i}$ are the independent variables and $e$ represents base of natural logarithms which is approximately equal to 2.718. In Equation 2, $Z$ can range from positive infinity to negative infinity. The probability of a farmer perceiving climate change lies between 0 and 1 . If we multiply both sides of the Equation 2 by $1+e^{-z_{i}}$ we get:

$$
\left(1+e^{-z_{i}}\right) P_{i}=1
$$

Dividing by $P$ and then subtract 1 leads to:

$e^{-z_{1}}=\frac{1}{P_{i}}=\frac{1-P_{i}}{P_{i}}$

By definition however, $e^{-z_{i}}=\frac{1}{e^{z_{i}}}=$ so that the Equation 4 becomes:

$$
e^{-z_{i}}=\frac{P_{i}}{1-P_{i}}
$$

By taking natural logarithm of both sides of Equation 5, we get:

$$
Z_{i}=\log \left(\frac{P_{i}}{1-P_{i}}\right)
$$

In other words:

$$
\log \left(\frac{P_{i}}{1-P_{i}}\right)=Z_{i}=\beta_{0}+\beta_{i} \chi_{i}
$$

This makes the logistic probability model. Therefore, it can be noted that the logistic model defined in the Equation 7 is based on the logits of $Z$, which constitutes the stimulus index. Marginal effects can also be computed to show changes in probability when there is a unit change in independent variables. Marginal effects are computed as:

$\frac{\partial P_{k}}{\partial \chi_{k}}=\frac{\beta_{k} e^{-z_{k}}}{\left(1+e^{-z_{k}}\right)^{z}}$

Therefore, this logistic regression model was used to determine those factors, which influenced farmers' perception on climate change. The dependent variable is farmers' perception of climate change, a binary variable indicating whether a farmer has perceived climate change. It was regressed on a set of relevant explanatory variables hypothesized based on literatures to have influence on perception to climate change, which are in Table 2. 
Table 2. Hypothesized explanatory variables and their descriptive statistics for logistic regression model, 2014

\begin{tabular}{|c|c|c|c|c|}
\hline Independent variables & Unit & Mean & $\begin{array}{l}\text { Std. } \\
\text { deviation }\end{array}$ & $\begin{array}{l}\text { Direction of } \\
\text { influence }\end{array}$ \\
\hline Sex (Gender) & Dummy: $1=$ Male, $0=$ Female & 0.708 & 0.4600 & $+/-$ \\
\hline Age (years) & Continuous & 43.830 & 10.5000 & $+/-$ \\
\hline Level of education $(e d u c)$ & Dummy: $1=$ primary and above, $0=$ no education & 0.530 & 0.5000 & + \\
\hline Experience in Agriculture (exp) & Continuous & 20.750 & 10.7200 & + \\
\hline Access to $\mathrm{CC}$ information (info) & Dummy: $1=$ Yes, 0 otherwise & 0.650 & 0.4789 & + \\
\hline Access to credit $(c r d t)$ & Dummy: $1=$ Yes, 0 otherwise & 0.690 & 0.4600 & + \\
\hline Access to extension (extn) & Dummy: $1=$ Yes, 0 otherwise & 0.750 & 0.4300 & + \\
\hline Access irrigation (irigt) & Dummy: $1=$ Yes, 0 otherwise & 0.370 & 0.4800 & $+/-$ \\
\hline Distance to Market (Dist) & Continuous & 10.820 & 6.2000 & - \\
\hline No. of livestock FHH has (TLU) & Continuous & 3.540 & 3.4700 & $+/-$ \\
\hline Off farm activities (offrm) & Dummy: $1=$ Yes, 0 otherwise & 0.250 & 0.4300 & $+/-$ \\
\hline Economic status of FHH (eco) & Dummy: $1=$ poor, $0=$ not poor & 1.570 & 0.6600 & $+/-$ \\
\hline Drought experience $(d r t)$ & Dummy: $1=$ Yes, 0 otherwise & 0.790 & 0.4100 & + \\
\hline Local Agro-ecology (agro) & Dummy: $1=$ highland, $0=$ lowland & 0.500 & 0.5004 & $+/-$ \\
\hline
\end{tabular}

Using these variables, the model is specified as:

$$
Z_{i}=\left(\beta_{i} \chi_{i}\right)+\varepsilon_{i}
$$

Where:

$Z_{i}=$ The perception by the $i^{\text {th }}$ farmer that climate is changing

$\chi_{I}=$ The vector of explanatory variables of probability of perceiving climate change by the $i^{\text {th }}$ farmer

$\beta_{I}=$ The vector of the parameter estimates of the regressors hypothesized to influence the probability of farmer is perception about climate change.

Accordingly, the empirical specification of the logistic regression model is:

$$
\begin{aligned}
& Z_{i}=\beta_{0}+\beta_{1} \operatorname{sex}+\beta_{2} \exp +\beta_{3} e d u c+\beta_{4} c r d t \\
& +\beta_{5} \text { inf } o+\beta_{6} \text { extn }+\beta_{7} \text { irigt }+\beta_{8} T L U+\beta_{9} \text { offrm }+ \\
& \beta_{10} e c o+\beta_{11} d r t+\beta_{12} \text { agro }+\beta 13 m k t d s t
\end{aligned}
$$

\section{Software Used}

Different software are used for this study. SPSS version 17 was used for performing statistical MannKendall test. The null hypothesis was tested at 95\% confidence level for annual, seasonal and monthly rainfall records. Theil Sen's slope for rainfall trend test was calculated using Single Case Research (SCR): A web based calculators for SCR analysis (Version 1.0) (Vannest et al., 2011). Besides, Stata software version 11 was used to run the logistics model. The null hypotheses were tested against 0.01 , 0.05 and 0.1 significance level in relation to the determinant factors. Other software like Microsoft Excel 2010 and ArcGIS 10 were also used.

\section{Results and Discussion}

\section{Monthly Rainfall Trends}

The rainfall system in Southern Tigray is a bimodal type where the main rainy season (Kiremt- JJAS) is preceded by a small rainy season (Belg-FMAM), as seen in Table 3 .

\section{At Stations Level}

Mann-Kendall results show all Belg rain-giving months (FMAM) at Maichew, three-fourth (FMM) at Alamata and two-in-four (FM) at Korem show negative signs in the time 1978-2012. Among those months, February at Alamata $(10 \mathrm{~mm} / \mathrm{d})$, at Korem (2 $\mathrm{mm} / \mathrm{d})$ and at Maichew (4 mm/d); May at Alamata (13 $\mathrm{mm} / \mathrm{d})$ and Korem $(19 \mathrm{~mm} / \mathrm{d})$ and March at Maichew station $(13 \mathrm{~mm} / \mathrm{d})$ showed decreasing trends all significant at 0.05 level.

Whereas, among Kiremt rain-giving months, 75\% (JAS) months in Maichew, 50\% (JnS) in Korem and $25 \%$ (S) in Alamata stations showed negative trends of rainfall, but only June at Maichew station was significant (10 $\mathrm{mm} /$ decade) at 0.05 level.

\section{At Agro-Ecological Level}

Results at agro-ecologic level are reflections of results at station level analysis. Hence, Table 4 show that February and May rainfall were drying significantly at 0.01 and 0.05 level in the lowland (kola) agro-ecological zone, while February rainfall trend was negative and significant at 0.05 level in the highlands.

Of the Kiremt rain-giving months, kola agro-ecologic zone had positive trend for all except September, with July and August significant at 0.01 and 0.05 level respectively. In the highland region, July and August rainfall trends showed increasing trend with the former significant at 0.01 level. 
Table 3. Average, Maximum and Minimum Annual and Seasonal Rainfall in Southern Tigray (1978-2012)

\begin{tabular}{|c|c|c|c|c|c|}
\hline Stations & Properties & Annual rainfall $(\mathrm{mm})$ & Kiremt rainfall $(\mathrm{mm})$ & Belg rainfall $(\mathrm{mm})$ & Bega rainfall $(\mathrm{mm})$ \\
\hline \multirow[t]{3}{*}{ Alamata } & Average & 668.40 & 341.48 & 241.25 & 85.70 \\
\hline & Max & 1003.53 & 768.70 & 445.80 & 226.00 \\
\hline & Min & 262.40 & 19.40 & 30.60 & 20.10 \\
\hline \multirow[t]{3}{*}{ Maichew } & Average & 787.13 & 457.82 & 219.97 & 109.34 \\
\hline & Max & 965.30 & 710.50 & 578.10 & 302.70 \\
\hline & Min & 477.70 & 158.00 & 31.40 & 25.40 \\
\hline \multirow[t]{3}{*}{ Korem } & Average & 983.40 & 591.22 & 237.83 & 154.35 \\
\hline & Max & 1380.20 & 979.10 & 505.80 & 333.60 \\
\hline & Min & 630.95 & 290.80 & 65.40 & 154.34 \\
\hline
\end{tabular}

Source: Calculated based on NMSA data series, 2014

Table 4. Trends of rainfall at monthly, seasonal and annual level in Southern Tigray, Northern Ethiopia (1978 to 2012)

\begin{tabular}{lcccrrr}
\hline & Highland & Lowlands & Regional & & & \\
Variables & Mann-K & Slope & Mann-K & Slope & Mann-K & Slope \\
\hline February & $-0.264^{*}$ & -3.190 & $-0.327^{*}$ & -9.67 & $-0.276^{*}$ & -6.25 \\
March & -0.194 & -9.130 & -0.086 & -8.04 & -0.113 & -6.98 \\
April & -0.012 & -0.170 & 0.009 & 0.62 & 0.025 & -2.45 \\
May & -219.000 & -12.330 & $-0.257^{*}$ & -13.33 & $-0.267^{*}$ & -18.90 \\
June & -0.153 & -4.210 & 0.169 & 1.50 & -0.106 & -1.82 \\
July & $0.324^{* *}$ & 34.710 & $0.517^{* *}$ & 52.69 & $0.422^{* *}$ & 38.80 \\
August & 0.138 & 13.860 & $0.252^{*}$ & 50.50 & 0.207 & 29.80 \\
September & -0.105 & -3.880 & -0.099 & 4.35 & -0.139 & -5.89 \\
Kiremt RF & $0.161^{\text {ns }}$ & 31.940 & $0.351^{* *}$ & 106.79 & $0.254^{*}$ & 55.16 \\
Belg RF & $-0.312^{* *}$ & -35.000 & $-0.204^{\text {ns }}$ & -33.47 & $-0.267^{*}$ & -36.25 \\
Annual RF & $-0.032^{\text {ns }}$ & -4.347 & $0.153^{\text {ns }}$ & 40.20 & $0.081^{\text {ns }}$ & 13.67 \\
\hline
\end{tabular}

Mann-K = Mann-Kendall trend test, Slope (Sen's slope) $=$ the change rainfall $(\mathrm{mm}) /$ decade; ns $=$ non-significant trend and $* *, *$ indicates significant trend at 0.01 and 0.05 significant level

Calculated based on NMSA data series, 2013

\section{At a Real (Regional) Level}

Although most of rain giving months of the two rainfall regimes have negative trends, regional scale analysis results show that the drying trend of February and May rainfalls were significant at 0,05 level, as in Table 4 above. July rainfall, on the other hand, had a significant positive trend at 0.01 level.

\section{Seasonal Rainfall Trends}

Kiremt rainfall is relatively higher in the highland agro-ecology whereas Belg rainfall is a bit higher in the lowland areas comparing to the highland shares. The annual share of Kiremt and Belg rains were 58.7 and $26.9 \%$ in the highland agro-ecology and 52.7 and $35.7 \%$ in lowland agro-ecological zone.

\section{At Station Level}

Mann-Kendall analysis show that Kiremt rainfall was significantly increasing in all but Maichew station. Magnitude of the positive trend ranges from $107 \mathrm{~mm} / \mathrm{d}$ in Alamata to $86 \mathrm{~mm} / \mathrm{d}$ in Korem station, all significant at 0.01 and 0.05 level respectively. Regarding Belg rainfall, all the three stations showed negative trends, but only Maichew's trend was significant $(44.5 \mathrm{~mm} / \mathrm{d})$ at 0.01 level.

\section{At Agro-Ecologic Level}

Table 4 indicates, Kiremt rainfall exhibited a significant positive trend for the lowlands (107 $\mathrm{mm} / \mathrm{d}$ ); whereas, Belg rainfall experienced significantly falling trend for highland areas. Rainfall during Belg season has an extreme inter-seasonal variability in the highland areas with $\mathrm{CV}$ values of above $47 \%$.

\section{At a Real Level}

As in Table 4 above, trend analysis results specified that while Kiremt rainfall significantly improved by 55.2 $\mathrm{mm} / \mathrm{d}$, Belg rainfall significantly lessened by 36.25 $\mathrm{mm} / \mathrm{d}$ at aggregate level.

\section{Annual Rainfall Trends}

Though Alamata $(40 \mathrm{~mm} / \mathrm{d})$ and Korem $(63 \mathrm{~mm} / \mathrm{d})$ stations recorded non-significant positive trends for annual rainfall, the decreasing trend for Maichew station was significant $(58 \mathrm{~mm} / \mathrm{d})$ at 0.05 level.

Besides, the interplay between the significant growth of Kiremt rainfall and significant decline in Belg rainfall did not cause any significant change in the trend of annual rainfall both at agro-ecologic or regional level, as shown in Table 4 above. 

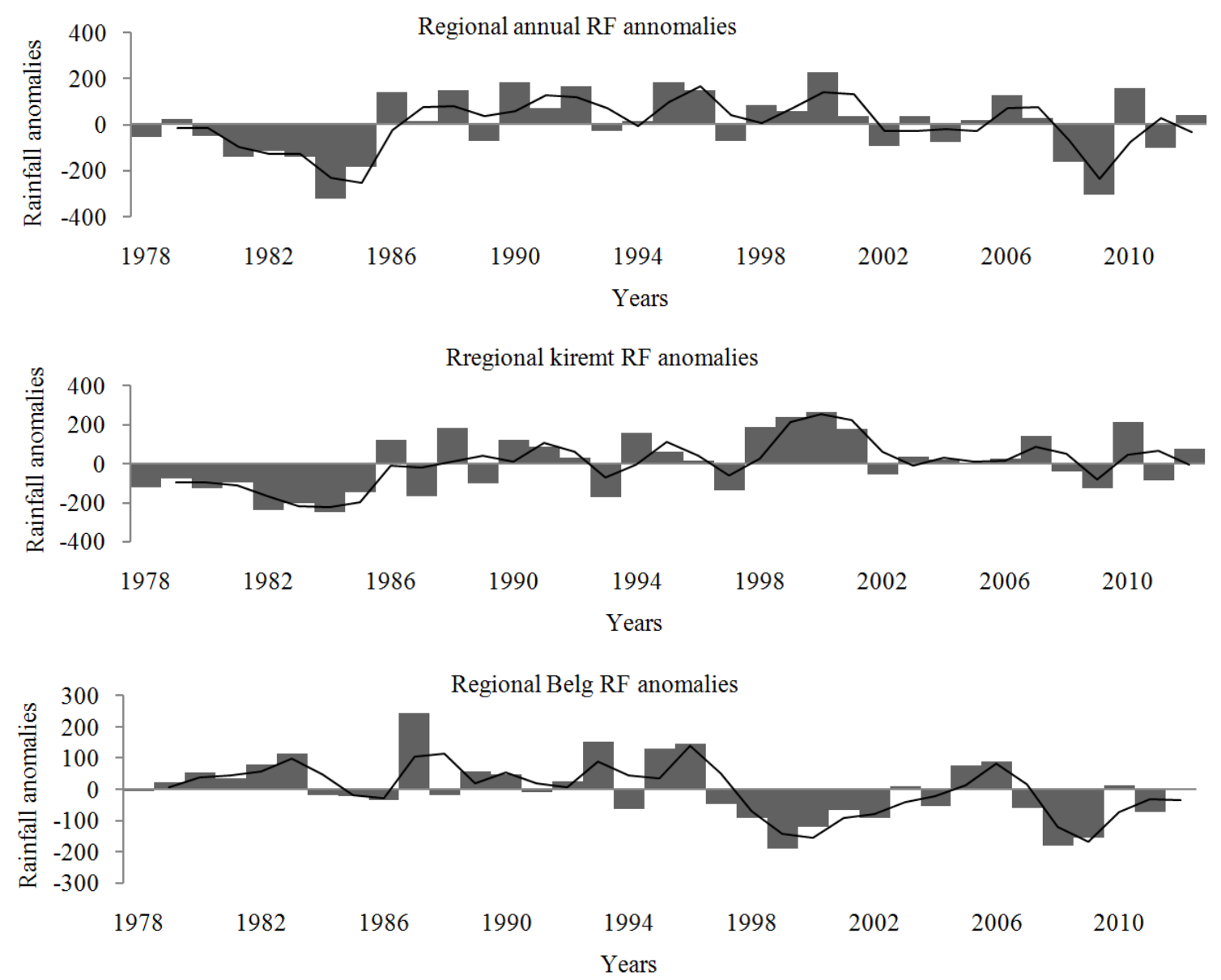

Source: Calculated based on NMSA data series, 2014

Fig. 4. Annual and seasonal rainfall anomalies with a two-year moving average (1978-2012)

As Fig. 4 below sows, annual and seasonal rainfalls experienced a comparable dry and wet seasons. The 1980s and the 2000s have particularly exhibited negative anomalies compared to the 1990s. Dry seasons particularly in the 1980 s caused the historic drought period of 1984 that resulted a famine that distracted the socio-economic system of communities in the study area.

Monthly rainfall results tell variation in spatiotemporal distribution of rainfall in the study area. It also indicates the gradual concentration of rainfall in to a few months to increase prevalence of lengthy dry-spells. The declining trends in February and May (in Belg season), June, and September (in Kiremt season) also designate commonness of late start and early ending of rainfall to affect number of rainy days (\&growing season) and crop production during the two rainy seasons. When rainfall comes late and ceased early, it does not only cause failure in harvest, but also delay in land preparation for next productive season and prevent planting of long cycle high-yielding crops (Maize and Sorghum) during
Belg season. DPPC and FAO have reported this phenomenon in their assessment of Belg production of the study area since 1997.

Seasonal rainfalls have shown different trends without having significant effect on annual rainfall amount of southern Tigray, according to results of Mann-Kendall trend analysis. The study found that while Kiremt rainfall grows significantly, Belg rainfall decreases significantly too. Some other studies also found positive trend for Kiremt rainfall in Northern Ethiopia. Studies by Seleshi and Zanke (2004) and Verdin et al. (2005) found non-significant trend for Kiremt rainfall over northern Ethiopia. Hadgu et al. (2013) reported a positive but non-significant trend for Kiremt rainfall at Alamata station in the period 1980 to 2009. While in northern central part of the country, Bewket (2009) learned positive trends for Kiremt rainfall in Lalibela and Desse stations. Regarding Belg rainfall, finding agrees with Hadgu et al. (2013) who found a declining trend at Alamata station. Dereje et al. (2012) also noticed a declining Belg trend in Srinka and 
Kombolacha stations, which are located in the northcentral highlands of the country near to the study area.

This significantly drying trend for Belg rainfall means a lot for local farmers who used to relay on Belg rains for food production. When it gets dry, production that could cover food demand of about two months is lost. For already food insecure community, having lost crop production in Belg season will jeopardize the food security problem in the study area.

Moreover, Belg rain was also important for availability of water and regeneration of grazing lands before Kiremt season starts. Farming households interviewed for this study were worried because they depend on Belg rains especially for land preparation and planting of long cycle high-yielding crops (Maize and sorghum). Elderlies point out that these two crops are the main food sources that sustain food demands of farming households for longer period comparing to other crop types.

Belg trend result may also tell the gradual transformation of the study area from a bimodal rainfall type to a mono-modal rainfall type, where rainfall will be available only in Kiremt season to result longer dry season following every Kiremt season. If this happens, the situation may disrupt water system, grazing land and livestock production besides decline in crop production.

\section{Perception of Farming Households on Rainfall Changes}

To investigate perception of farmers on climate change, farming households were asked to state what they had observed regarding long-term changes in precipitation and temperature. They were further asked to specify what they had observed specifically; increase, decrease or no change. The results of this analysis are presented below.

Regarding temperature, more than three-fourth of respondents perceived temperature change in day and night time. While $85.5 \%$ of farming households felt warmer temperature at daytime, $88.5 \%$ stated that nighttime temperature has increased.

Survey results on temperature trends show variation by agro ecology. While $96 \%$ of respondents from the lowlands felt an increase in day temperature, $75 \%$ of respondents from highland agro ecology believed daytime temperature has grown up. Chi square test results on daytime temperature indicated a significant variation in perception of farming community by agro ecology, $\chi^{2}(2, \mathrm{~N}=600)=55.3, \mathrm{p}<0.001$. Besides, $89.7 \%$ respondents from lowland and $87.7 \%$ from highland perceived a warming nighttime temperature in their locality. Similarly, for night time temperature, perception of farming households was found significant by agro-ecology zone, $\chi^{2}(2, \mathrm{~N}=600)=23.75, \mathrm{p}<0.001$.
As to perception on precipitation, an average of $75 \%$ respondents have observed a declining trend. Chi-square test results show that perceptions of farming households significantly vary by agro ecological zone, $\chi^{2}(1, \mathrm{~N}=600)$ $=13.5, \mathrm{p}<0.001$. While $13 \%$ more respondents from the lowland agro-ecology perceived decline in rainfall. Variations in rainfall characteristics between the two agro-ecological zones and the spatio-temporal variations in climate related events such as localized droughts, negative anomalies and rainfall irregularities may have influenced farmers to vary senses to climate trends.

Furthermore, farming households were asked to specify what type of change they observed for rainfall and temperature in the last two decades. There was some variation in perception especially in seasonal rainfall. Out of 600 respondents, $50 \%$ (55\% from lowlands and $44 \%$ from highlands) perceived a non-declining Kiremt rainfall (no change and positive trend) in last two decades. Only $45 \%$ of farming households form lowlands and $56 \%$ from highland felt a declining rainfall during Kiremt season. The variation in perception on Kiremt rainfall was significant at agro-ecological level, $\chi^{2}(1, \mathrm{~N}=600)=6.83, \mathrm{p}<0.001$.

On the other hand, about $85 \%$ of farming households from the lowlands and $89 \%$ from the highland agroecological areas presumed a decline trend for Belg rainfall, with no significant variation across study area.

Knowing whether farmers' perceptions on climate change are consistent with reality (statistical findings) is important step in adaptation practices. Perception should be consistent with realities in order to have effective adaptation practices. When farmers' perception is different from reality, their decisions to respond to climate change at right time and space would deviate, thus, it becomes risky for farmers.

Mann-Kendall trend results show an increasing Kiremt rainfall and a declining Belg rain in the last three decades (1980-2012) across all scale. It seems there was lack of congruence between trend analysis results and perception, but not exactly. For the last two decades (1990-2010), Kiremt rainfall does not show any trend (zero trend), whereas, Belg was declining. Therefore, perceptions of farming households on seasonal rainfall for the last two decades can be considered consistent with MannKendall analysis results.

From discussion with elder members of community, we understood that, farmers evaluate rainfall seasons in view of whether it has effected good production at particular time. Small change in quantity of rain, the timing of onset, cessation dates and frequency and duration of dry spells might cause serious effects in farmers' production and livelihoods. To that level, rainfall in the study area was erratic and unreliable that resulted for crop reduction and failure (FAO, 2009). 
On the association between household characteristics and perception, cross tabulation with chi-square test was carried out. About 93\% of farming households who perceived Kiremt and Belg rainfall declining were found in the age group of 31-64 years. The variations in perception across age were significant, $\chi^{2}(4, \mathrm{~N}=600)=$ $10.85, \mathrm{p}<0.05$ for Kiremt and $\chi^{2}(4, \mathrm{~N}=600)=70.23$, $\mathrm{p}<0.05$ for Belg rains. Chi-square results show substantial association between experience and perception, as experience is associated with age of farmers. Among those who perceived a declining Belg rainfall, $82 \%$ had farming experience of more than 10 years. Besides, about $42 \%$ of those perceived were those who attained primary education at least.

\section{Determinants of Perception on Rainfall Change}

Farmers should perceive changes in the climate situations to respond effectively through adaptation practices. It is through adaptation that they can minimize adverse effects of climate change in their agricultural production in particular and livelihoods in general. However, ability of farming households to perceive climate change is affected by various socioeconomic and institutional factors. Table 5 below presents the logistic regression coefficient together with marginal effects after the dependent variable (perception) was regressed on a set of explanatory variables that have been discussed beforehand. Yet, we discussed those factors that had significant influence on farmers' perception to climate change in southern Tigray; the others can be seen from the table.

About $93 \%$ of farming households who perceived Kiremt and Belg rainfall declining were found in the age group of 31-64 years. Chi-square results indicate that variations in perception across age were significant, $\chi^{2}(4, \mathrm{~N}=600)=10.85, \mathrm{p}<0.05$ for Kiremt and $\chi^{2}(4, \mathrm{~N}=$ $600)=70.23, \mathrm{p}<0.001$ for Belg rains. Chi-square results also show substantial association between experience and perception, as experience is associated with age of farmers. Age was put out of the model due to its multi-collinearity effect with experience and some other predictor variables.

Further, econometric model also shows that among household characteristics, sex, level of education and farming experience positively and significant influenced perception to climate change. Farming household heads with education and more farming experience are more likely to perceive changes in climate than those with less farming experience and less education. The point that education and farming experience have significant association with perception implies the capability of experienced and educated farmers to better access information about climate change compared to those with less experienced and uneducated. Studies show that with more experience and education, farmers develop knowledge and skill that may help them sense risks better (Maddison, 2007; Gibetibouo, 2009; Deressa et al., 2010).

Male-headed households are highly likely by $7 \%$ more to perceive climate change compared to femaleheaded farming households. This might be due to the fact that females are confined more to house and agricultural works for most of days that make them have less chance of sharing information with others relative to males. Male farmers move between places in such a way that they can meet people and mass media to share experiences and idea about contemporary climate. Maddison (2007; Deressa et al., 2010); however, found no variation in perception of climate change because of gender.

Among the factors related to institutional features, access to climate information, extension and credit services showed positive effects on farmers' perception to climate change. While 76 and $55 \%$ of respondents had access to extension and credit services respectively, about $60 \%$ respondents get climate information from agricultural Development Agents (DAs), Radio/TV and local leader.

While, probability of observation increases by 5.4 and $10.1 \%$ more with access to extension and climate information respectively, it decreases by $11 \%$ with access to irrigation. Albeit $55 \%$ of respondents have access to credit, it was found not significant to affect perception of climate change. This might be for the reason that those farmers with irrigation access may not feel the pressure of water stress other farmers are feeling due to shortage of rainfall and lengthy dry spells. Maddison (2007; Deressa et al., 2010) have reported similar result on access to extension services that it significantly influenced perception of climate change.

Moreover, $37 \%$ of respondents have access to irrigation services and the average distance between respondents' localities and nearby market center was about $10.8 \mathrm{KM}$.

Besides, economic status of farming households, exposure to drought and agro-ecology were found to have positive and significant influence on farmers' perceptions on climate change. The more economically secured farmers are the more likely they will be to perceive climate change. Survey results show that while about $54.5 \%$ of respondents have off-farm earnings, some $52 \%$ were economically poor households. In addition, logistics model results show Economic security might pave chances for farming households to have access to media, such as radio/TV and other means to get access to climate information, which would help them to understand what is going on in their environment. Contrary to our findings, Deressa et al. (2010) reported that farmers with farm income are more likely to perceive climate change than those with off-farm incomes. 
Table 5. Results of the logistic regression model and marginal effects for perception of farming households to climate change in Northern Ethiopia, 2014

\begin{tabular}{|c|c|c|}
\hline Rainfall decreased & Logistic R. Coef. & Marginal effect Dy/dx \\
\hline$\overline{\operatorname{Sex}}$ & $0.640^{* *}$ & $0.070^{* *}$ \\
\hline Education level & $1.158^{* * *}$ & $0.126^{* * *}$ \\
\hline Farm experience (yrs) & $0.402^{* *}$ & $0.044^{* *}$ \\
\hline Access to extension & $0.497^{*}$ & $0.054^{*}$ \\
\hline Access to climate info & $0.928^{* * *}$ & $0.101^{* * *}$ \\
\hline Access to credit & 0.025 & 0.003 \\
\hline Access to irrigation & $-1.02^{* * *}$ & $-0.111^{* * *}$ \\
\hline Livestock possession (TLU) & $-0.003^{*}$ & $-0.0003^{*}$ \\
\hline Distance to market center & -0.017 & -0.002 \\
\hline Off-farm activities & $0.622^{* *}$ & $0.068^{* *}$ \\
\hline Economic status & $0.606^{* *}$ & $0.066^{* *}$ \\
\hline Drought exposure & $2.14^{* * *}$ & $0.234^{* * *}$ \\
\hline Local agro-ecology & $1.05^{* * *}$ & $0.114^{* * *}$ \\
\hline Constant & $-3.12^{* * *}$ & \\
\hline Observation & 600.00 & \\
\hline Log likelihood & -211.276 & \\
\hline $\operatorname{LR~X}^{2}(13)$ (p-value) & $254.44(0.000)$ & \\
\hline Pseudo $\mathrm{R}^{2}$ & 0.3758 & \\
\hline
\end{tabular}

Note: $* * * * *, *$ indicate significant at 1,5 and $10 \%$ level of significant respectively

Farmers predominantly dependent on farm income might sense climate change better; however, those who sensed the change take decision to respond through different ways of adaptation. In this scenario, those who perceived climate change tend to diversify their income realizing that farm income alone would no more be enough for their future livelihoods.

\section{Conclusion}

Mann-Kendall trend analysis results for monthly, seasonal and annual at station, agro-ecological and areal based have shown significant insights about how regional climate is changing in southern Tigray. Monthly rainfall in February, March and May experienced significant declining trend in at least two of the three stations. All Belg rain-giving months had also negative rainfall trends at the highland agroecological area.

Among Kiremt rain-giving months, July and August at Alamata and July at Korem station showed significant increasing rainfall trends. Yet at Maichew station, except July that had a non-significant positive trend all the three months had negative rainfall trends. Consequently, rainfall during Kiremt season at Alamata $(107 \mathrm{~mm} / \mathrm{d})$ and Korem $(86 \mathrm{~mm} / \mathrm{d})$ station increased significantly. The trend was also significant at the areal level.

Belg rainfall, contrary to the Kiremt one, exhibited a declining trend in all the stations, but the declining trend was significant at Maichew station $(44.5 \mathrm{~mm} / \mathrm{d})$. As a result, Belg rains in the highland agro-ecological area $(35 \mathrm{~mm} / \mathrm{d})$ and the study region $(36 \mathrm{~mm} / \mathrm{d})$ in general had shown significant drying trends.

Despite the findings of increasing trend in Kiremt rainfall at Alamata and Korem stations and decreasing trend of Belg rainfall at a real level, annual rainfall did not show any significant trend at regional level. Nevertheless, a significant declining trend was consequently found particularly at Maichew station since end of 1970 s.

With regard to perceptions of farming households, about $75 \%$ of respondents perceived change in rainfall in their localities. More or less the perception by the farming community was consistent with reality from the Mann-Kendal trend analysis, especially of the last two decades. There was significant variation in perception among respondents by agro-ecology. Otherwise, farming communities perceived well about the declining trend of Belg rainfall in all districts, which were in accordance with Mann-Kendall trend analysis results. Perceptions of farming households are; however, reliant on various factors. Among the group, this study have found education level, farming experience, access to extension services and climate information, off-farm income and having exposure to drought and local agro-ecology positively and significantly affecting farmers perception to climate change. Access to irrigation and livestock possession 
showed significant negative effects on perception to climate change.

Subsequently, more of the factors found to have affected perception of farming households on climate change are related to institutional and infrastructural developments. Therefore, a lot has to be done in awareness creation works on climate change at local and regional level. Substantial works related to local knowledge inclusive farm level adaptation approaches, environmental conservation works, small and medium irrigation developments and protection of livelihoods in general are suggested to combat the effect of this threatening trend in climate change in the study area.

\section{Acknowledgement}

This study was carried out with the support of various organizations. We acknowledged efforts of NMSA, Mekelle branch for supplying necessary climatic data and Aksum University for delivering financial support to carry out survey for this study.

\section{Author's Contributions}

Misgina Gebrehwot Abrha: Designing and organizing the study, data collecting (primary and secondary), data entry and statistical analysis, writing the manuscript and reading and approving final version for submission.

S. Simhadri: Designing and organizing the study, Mentorship works and Reading and approving final version for submission.

\section{Ethics}

We, the authors, declare no conflict of interest regarding this work.

\section{References}

Admassie, A. and B. Adenew, 2007. Stakeholders' perceptions of climate change and adaptation strategies in Ethiopia. EEA Research Report. Addis Ababa, Ethiopians Economic Association, Ethiopia.

Awulachew, S., T. Erkossa, and R. Namara, 2010. Irrigation potential in Ethiopia: Constraints and opportunities for enhancing the system. Report for IWMI.

Bewket, W., 2009. Rainfall variability and crop production in Ethiopia case study in the Amhara region. Proceedings of the 16th International Conference of Ethiopian Studies, Trondheim, pp: 823-836.

Blackwell, P., 2012. Kendall's Tau.
Christensen, J., B. Hewitson and L. Mearns, 2007. Regional climate projections, in climate change 2007: The physical science basis: Contribution of working group I to the fourth assessment report of the intergovernmental panel on climate change. Cambridge University Press, Cambridge, UK.

Conway, D. and E.L.F. Schipper, 2011. Adaptation to climate change in Africa: Challenges and opportunities identified from Ethiopia. Global Environ. Change, 21: 227-237.

DOI: $10.1016 /$ j.gloenvcha.2010.07.013

CSA, 2012. Projected population of Ethiopia for 2013. Central Statistics Agency (CSA), Addis Ababa, Ethiopia.

Dereje, A., T. Kinde, M. Girma, Y. Birru and B. Wondimu, 2012. Variability of rainfall and its current trend in Amhara region, Ethiopia. Afr. J. Agric. Res., 7: 1475-1486.

DOI: $10.5897 / A J A R 11.698$

Deressa, T.T., R.M. Hassan and C. Ringler, 2010. Perception of and adaptation to climate change by farmers in the Nile Basin of Ethiopia. J. Agric. Sci., 149: 23-31. DOI: 10.1017/S0021859610000687

DPPC, 1999. Ethiopian early warning system monthly report. Disaster Prevention and Preparedness Commission (DPPC), Addis Ababa - Ethiopia.

DPPC, 2004. Ethiopian early warning system. Disaster Prevention and Preparedness Commission (DPPC), Addis Ababa - Ethiopia.

DPPC, 2006. Belg and pastoral area assessment and food requirement. Disaster Prevention and Preparedness Commission (DPPC), Addis Ababa.

Drapela, K. and I. Drapelova, 2011. Application of Mann-Kendall test and the Sen's slope estimates for trend detection in deposition data from Bílý Kř́ž (Beskydy Mts., the Czech Republic) 1997-2010. Brno, 4: 133-146.

FAO, 2008. FAO/WFP crop and food security assessment mission to Ethiopia (Phase 2), special report. FAO Global Information and Early Warning System on Food and Agriculture FAO/World Food Programme.

FAO, 2009. FAO/WFP Crop and food security assessment mission to Ethiopia, special report. FAO Global Information and Early Warning System on Food and Agriculture FAO/World Food Programme.

Feder, G., R. Just and D. Zilberman, 1985. Adoption of agricultural innovations in developing countries: A survey. Economic Dev. Cultural Change, 33: 255-98. DOI: 10.1086/451461

Gibetibouo, G.A., 2009. Understanding farmers' perceptions and adaptations to climate change and variability. The case of the Limpopo basin, south Africa. International Food Policy Research Institute (IFPRI), Washington DC. 
Gonzalez-Rouco, J., J. Luis, V. Quesada and F. Valero, 2011. Quality control and homogeneity of precipitation data in the southwest of Europe. J. Climate, 14: 964-978. DOI: 10.1175/15200442(2001)014<0964:QCAHOP > 2.0.CO;2

Gujarati, D.M., 2003. Basic Econometrics. 4th Edn., McGrawHill/Irwin, New York, ISBN-10: 0071123423, pp: 1002.

Hadgu, G., K. Tesfaye, G. Mamo and B. Kassa, 2013. Trend and variability of rainfall in Tigray, Northern Ethiopia: Analysis of meteorological data and farmers' perception. Academia J. Agric. Res., 1: 088-100.

Karpouzos, D., S. Kavalieratou and C. Babajimopoulos, 2010. Trend analysis of Precipitation data in Pieria Region (Greece). Eur. Water, 30: 31-40. http://digital.lib.auth.gr/record/131069

Kendall, M.G., 1975. Rank Correlation Methods. 1st Edn., Griffin, Bristol, pp: 272.

Komba, C. and E. Muchapondwa, 2012. Adaptation to Climate Change by Smallholder Farmers in Tanzania. ERSA working paper 299. Economic Research Southern Africa (ERSA).

Maddison, D., 2007. The perception of and adaptation to climate change in Africa. Policy Research Working Paper 4308. The World Bank Development Research Group Sustainable Rural and Urban Development Team.

MARD, 2009. Tigray Regional Overview and Livelihood Zone Summaries. Disaster Management and Food Security Sector. Livelihoods integration unit/Ministry of Agriculture and Rural Development (MARD), Addis Ababa.

Mavromatis, T. and D. Stathis, 2011. Response of the water balance in Greece to temperature and precipitation trends. Theoretical Applied Climatol., 104: 13-24. DOI: 10.1007/s00704-010-0320-9

Meze-Hausken, E., 2004. Contrasting climate variability and meteorological drought with perceived drought and climate change in northern Ethiopia. Climate Res., 27: 19-31.

DOI: $10.3354 / \mathrm{cr} 027019$

Motiee, H. and E. McBean, 2009. An assessment of long-term trends in hydrologic components and implications for water levels in Lake Superior. Hydrol. Res., 40: 564-579.

DOI: $10.2166 /$ nh.2009.061

Ndambiri, H.K., C. Ritho, S. Mbogoh, S.I. Ng'ang'a and E.J. Muiruri et al., 2012. Analysis of farmers' perceptions of the effects of climate change in Kenya: the case of Kyuso district. J. Environ. Earth Sci., 2: 74-83.
Ngongondo, C., C. Yu-Xu, L. Gottschalk and B. Alemaw, 2011. Evaluation of spatial and temporal characteristics of rainfall in Malawi: A case of data scarce region. Theor. Applied Climatol., 106: 76-93. DOI: 10.1007/s00704-011-0413-0

Nicholson, S., 1985. Sub-Saharan rainfall 1981-84. J. Climate Applied, 24: 1388-1391. DOI: 10.1175/1520-0450(1985)024<1388:SSR > 2.0.CO;2

NMA, 2007. Climate change National Adaptation Programme of Action (NAPA) of Ethiopia. The Federal Democratic Republic of Ethiopia Ministry of Water Resources, National Meteorological Agency, Addis Ababa, Ethiopia.

Onoz, B. and M. Bayazit, 2012. The power of statistical tests for trend detection. Turkish J. Eng. Environ. Sci., 27: 247-251.

Partal, T. and E. Kahya, 2006. Trend analysis in Turkish precipitation data. Hydrol. Proc., 20: 2011-2026. DOI: 10.1002/hyp.5993

Patino, L. and A.D. Gauthier, 2009. Integrating local perspectives into climate change decision making in rural areas of the Canadian prairies. Int. J. Climate Change Strategies Manage., 1: 179-196. DOI: $10.1108 / 17568690910955630$

Posthumus, H., C. Gardebroek and R. Ruerd, 2010. From participation to adoption: Comparing the effectiveness of soil conservation programs in the Peruvian Andes. Land Econom., 86: 645-667. DOI: $10.3368 /$ le.86.4.645

Prager, K. and H. Posthumus, 2010. Socio-Economic Factors Influencing Farmers' Adoption of Soil Conservation Practices in Europe. In: Human Dimensions of Soil and Water Conservation, Napier, T.L. (Ed.), Nova Science Pub Inc., ISBN-10: 1617289574, pp: 203-223.

Seleshi, Y. and U. Zanke, 2004. Recent changes in rainfall and rainy days in Ethiopia. Int. J. Climatol., 24: 973-983. DOI: 10.1002/joc. 1052

Sen, P., 1968. Estimates of the regression coefficient based on Kendall's tau. J. Am. Stat., 63: 1379-1389. Doi: 10.1080/01621459.1968.10480934

Tabari, H., S. Marofi, A. Aeini, P. Talaee and K. Mohammadi, 2011. Trend analysis of reference evapotranspiration in the Western half of Iran. Agric. Forest Meteorol., 151: 128-136. DOI: 10.1016/j.agrformet.2010.09.009

Vannest, K., R. Parker and O. Gonen, 2011. Single Case Research: web based calculators for SCR analysis. College Station, TX: Texas A\&M University.

Verdin, J., C. Funk, G. Senay and R. Choularton, 2005. Climate science and famine early warning. Philos. Trans. R Soc. Lond B Biol. Sci., 360: 2155-68. PMID: 16433101 
Vste, E., K. Driba and S. Asgeir, 2013. Recent drought and precipitation tendencies in Ethiopia. Theor. Appl. Climatol., 112: 535-551.

DOI: $10.1007 / \mathrm{s} 00704-012-0746-3$

WB, 2003. Africa Rainfall and Temperature Evaluation System (ARTES). The World Bank, Washington.

Yenigun, K., V. Gumus and H. Bulut, 2008. Trends in streamflow of Euphrates Basin, Turkey. Water Manage., 161: 189-198.

DOI: 10.1680/wama.2008.161.4.189
Yue, S. and C. Wang, 2004. The Mann-Kendall test modified by effective sample size to detect trend in Serially correlated hydrological series. Water Resources Manage., 18: 201-218.

DOI: 10.1023/B:WARM.0000043140.61082.60 